\title{
AN EXTENSION OF BANACH'S MAPPING THEOREM
}

\author{
RICHARD A. BRUALDI ${ }^{1}$
}

The following mapping theorem of Banach [1] is well known. It is the basis of most proofs of the Schroder-Bernstein equivalence theorem.

If $X$ and $Y$ are sets and $f: X \rightarrow Y$ and $g: Y \rightarrow X$ are injective mappings, then there exists partitions ${ }^{2} X=X_{1}+X_{2}$ and $Y=Y_{1}+Y_{2}$ such that $f\left(X_{1}\right)=Y_{1}$ and $g\left(Y_{2}\right)=X_{2}$.

The conclusion of this theorem can be rephrased in the following way.

Let $\Lambda \subseteq X \times Y$ be the relation between $X$ and $Y$ defined by

$$
\Lambda=\Lambda_{f} \cup \Lambda_{0}^{-1}
$$

where

$$
\Lambda_{f}=\{(x, f(x)): x \in X\}, \quad \text { the graph of } f
$$

and

$$
\left.\Lambda_{0}^{-1}=\{(g(y)), y): y \in Y\right\}, \quad \text { the graph of } g^{-1} .
$$

Then there exists a bijection $h: X \rightarrow Y$ with graph $\Lambda_{h} \subseteq \Lambda$. With this, we are now prepared to state the main result of this paper which extends the above theorem of Banach. For sets $U$ and $V, U \backslash V$ is the set consisting of those elements of $U$ which are not in $V$.

1. Theorem. Let $X$ and $Y$ be sets with given partitions $\sum_{i \in I} X_{i}$ and $Y=\sum_{j \in J} Y_{j}$ where $I$ and $J$ are arbitrary index sets. For each $i \in I$, let integers $a_{i}$ and $a_{i}^{\prime}$ be specified with $0 \leqq a_{i} \leqq a_{i}^{\prime}$. For each $j \in J$, let integers $b_{j}$ and $b_{j}^{\prime}$ be specified with $0 \leqq b_{j} \leqq b_{j}^{\prime}$. Suppose $f: X^{0} \rightarrow Y^{0}$ is a bijection where $X^{\circ} \subseteq X$ and $Y^{\circ} \subseteq Y$ with

$$
\begin{array}{ll}
a_{i} \leqq\left|X_{i} \backslash X^{0}\right| & (i \in I), \\
\left|Y_{j} \backslash Y^{0}\right| \leqq b_{j}^{\prime} & (j \in J),
\end{array}
$$

and suppose $\mathrm{g}:{ }^{0} Y \rightarrow{ }^{0} X$ is a bijection where ${ }^{0} Y \subseteq Y$ and ${ }^{0} X \subseteq X$ with

$$
\begin{aligned}
& \left|X_{i} \backslash^{0} X\right| \leqq a_{i}^{\prime} \quad(i \in I), \\
& b_{j} \leqq\left|Y_{j} \backslash^{0} Y\right| \quad(j \in J) .
\end{aligned}
$$

Let $\Lambda=\Lambda_{f} \cup \Lambda_{\theta^{-1}}$ where $\Lambda_{f}$ and $\Lambda_{o^{-1}}$ are the graphs of $f$ and $g^{-1}$ respec-

Received by the editors November 2, 1967.

1 Partially supported by National Science Foundation Grant No. GP-7073.

2 $X=X_{1}+X_{2}$ is a partition of $X$ if $X=X_{1} \cup X_{2}$ and $X_{1} \cap X_{2}=\varnothing$. 
tively. Then there exist $X^{\prime} \subseteq X$ and $Y^{\prime} \subseteq Y$ with

$$
\begin{array}{ll}
a_{i} \leqq\left|X_{i} \backslash X^{\prime}\right| \leqq a_{i}^{\prime} & (i \in I), \\
b_{j} \leqq\left|Y_{j} \backslash Y^{\prime}\right| \leqq b_{j}^{\prime} & (j \in J),
\end{array}
$$

and a bijection $h: X^{\prime} \rightarrow Y^{\prime}$ with graph $\Lambda_{\theta} \subseteq \Lambda$.

ReMARKs. (a) $X=\sum_{i \in I} X_{i}$ is a partition means $X=\bigcup_{i \in I} X_{i}$ and $X_{i} \cap X_{i^{\prime}}=\varnothing$ for all $i \neq i^{\prime}$ in $I$.

(b) It is possible that the cardinalities $\left|X_{i} \backslash X^{0}\right|$ and $\left|Y_{j} \backslash^{0} Y\right|$ be infinite.

(c) If $I=\{1\}$ and $J=\{1\}$ so that the partitions of $X$ and $Y$ are trivial and if $a_{1}=a_{1}^{\prime}=b_{1}=b_{1}^{\prime}=0$, then the above theorem reduces to Banach's mapping theorem. For under these circumstances $g^{-1}: X \rightarrow Y$ and $f^{-1}: Y \rightarrow X$ are injective mappings and $X^{\prime}=X, Y^{\prime}=Y$.

2. Proof of the theorem. If we restrict the injective mapping $f$ to a subset of $X^{0}$, then condition (1) will still be satisfied. Hence we may assume at the start that

$$
b_{j} \leqq\left|Y_{j} \backslash Y^{0}\right| \leqq b_{j}^{\prime} \quad(j \in J) .
$$

Let $i \in I$. If $a_{i} \leqq\left|X_{i} \backslash X^{0}\right| \leqq a_{i}^{\prime}$, then define $X_{i}^{1}=\varnothing$. If on the other hand $\left|X_{i} \backslash X^{0}\right|>a_{i}^{\prime}$, then from (3) we conclude that $\left|\left(X_{i} \backslash X^{0}\right) \backslash^{0} X\right|$ $\leqq a_{i}^{\prime}$, so that there exists $X_{i}^{1} \subseteq\left(X_{i} \backslash X^{0}\right) \cap^{0} X$ such that

$$
a_{i} \leqq\left|X_{i} \backslash\left(X^{0} \cup X_{i}^{1}\right)\right| \leqq a_{i}^{\prime} .
$$

Define $X^{1}$ and $P^{1}$ by $X^{1}=P^{1}=\cup_{i \in I} X_{i}^{1}$ and define $U^{1}=\varnothing$, so that

$$
a_{i} \leqq\left|X_{i} \backslash\left(\left(X^{0} \backslash U^{1}\right) \cup P^{1}\right)\right| \leqq a_{i}^{\prime} \quad(i \in I) .
$$

Note that $P^{1} \subseteq{ }^{0} X \backslash X^{0}$. If $P^{1}=\varnothing$, then $X^{\prime}=X^{0}, Y^{\prime}=Y^{0}, h=f$ satisfy the conclusion of the theorem. Hence we can assume $P^{1} \neq \varnothing$. We proceed inductively. Let $n \geqq 1$ and suppose the following six families of sets have been defined, each family consisting of mutually disjoint sets:

(7) $\left\{X^{k} \subseteq X: 1 \leqq k \leqq n\right\} \quad$ with $X^{1} \subseteq{ }^{0} X \backslash X^{0}$ and $X^{k} \subseteq X^{0} \quad(1<k \leqq n)$,

$$
\begin{gathered}
\left\{P^{k} \subseteq{ }^{0} X \backslash X^{0}: 1 \leqq k \leqq n\right\}, \\
\left\{U^{k} \subseteq X^{0} \backslash{ }^{0} X: 1 \leqq k \leqq n\right\}, \\
\left\{Y^{k} \subseteq{ }^{0} Y: 1 \leqq k<n\right\}, \\
\left\{Q^{k} \subseteq{ }^{0} Y \backslash Y^{0}: 1 \leqq k<n\right\}, \\
\left\{V^{k} \subseteq Y^{0} \backslash{ }^{0} Y: 1 \leqq k<n\right\},
\end{gathered}
$$

with 


$$
a_{i} \leqq\left|X_{i} \backslash\left(\left(X^{0} \backslash \bigcup_{k=1}^{n} U^{k}\right) \cup \bigcup_{k=1}^{n} P^{k}\right)\right| \leqq a_{i}^{\prime} \quad(i \in I)
$$

and

$$
b_{j} \leqq\left|Y_{j} \backslash\left(\left(Y^{0} \backslash \bigcup_{k=1}^{n-1} V^{k}\right) \cup \bigcup_{k=1}^{n-1} Q^{k}\right)\right| \leqq b_{j}^{\prime} \quad(j \in J) .
$$

(If $n=1$, then $\bigcup_{k-1}^{n=1} V^{k}=\bigcup_{k=1}^{n-1} Q^{k}=\varnothing$.) We then define

$$
\begin{aligned}
& Y^{n}=g^{-1}\left(\left(X^{n} \backslash U^{n}\right) \cup P^{n}\right), \\
& Q_{j}^{n}=\left(Y^{n} \cap Y_{j}\right) \backslash Y^{0} \quad(j \in J), \\
& Q^{n}=\bigcup_{j \in J} Q_{j}^{n} \subseteq{ }^{0} Y \backslash Y^{0} .
\end{aligned}
$$

Since for each $j \in J,\left|Y_{j} \backslash Y^{0}\right| \leqq b_{j}^{\prime}<\infty, Q_{j}^{n}$ is a finite set. If for $j \in J$,

$$
b_{j} \leqq\left|Y_{j} \backslash\left(\left(Y^{0} \backslash \bigcup_{k=1}^{n-1} V^{k}\right) \cup \bigcup_{k=1}^{n} Q^{k}\right)\right| \leqq b_{j}^{\prime},
$$

we define $V_{j}^{n}=\varnothing$. Otherwise

But then

$$
\left|Y_{j} \backslash\left(\left(Y^{0} \backslash \bigcup_{k=1}^{n-1} V^{k}\right) \cup \bigcup_{k=1}^{n} Q^{k}\right)\right|<b_{j}
$$

$$
\begin{aligned}
\mid\left(\left(\left(Y_{j} \backslash 0\right) \backslash \bigcup_{k=1}^{n-1} V^{k}\right)\right. & \left.\cap Y^{0}\right) \mid \\
& \geqq b_{j}-\mid Y_{j} \backslash\left(\left(Y^{0} \backslash \bigcup_{k=1}^{n-1} V^{k}\right) \cup \bigcup_{k=1}^{n} Q^{k}\right)_{i} .
\end{aligned}
$$

for otherwise

$$
\begin{aligned}
\left|Y_{j} \backslash^{0} Y\right| \leqq & \left|\left(\left(Y_{j} \backslash{ }^{0} Y\right) \backslash \bigcup_{k=1}^{n-1} V^{k}\right) \cap Y^{0}\right| \\
& +\left|Y_{j} \backslash\left(\left(Y^{0} \backslash \bigcup_{k=1}^{n-1} V^{k}\right) \cup \bigcup_{k=1}^{n} Q^{k}\right)\right|<b_{j},
\end{aligned}
$$

which would be a contradiction. Hence we may choose $V_{j}^{n}$ $\subseteq\left(\left(Y_{j} \backslash^{0} Y\right) \backslash \bigcup_{k=1}^{n-1} V^{k}\right) \cap Y^{0}$ with

$$
\left|V_{j}^{n}\right|=b_{j}-\left|Y_{j}\right\rangle\left(\left(Y^{0} \backslash \bigcup_{k=1}^{n-1} V^{k}\right) \cup \bigcup_{k=1}^{n} Q^{k}\right) \mid \text {. }
$$

Define $V^{n}=\cup_{j \in J} V_{j}^{n} \subseteq Y^{0} \backslash^{0} Y$ so that 


$$
b_{j} \leqq\left|Y_{j} \backslash\left(\left(Y^{0} \backslash \bigcup_{k=1}^{n} V^{k}\right) \cup \bigcup_{k=1}^{n} Q^{k}\right)\right| \leqq b_{j}^{\prime} \quad(j \in J) .
$$

For $n=1$ each of the families (7), (8), (9) are families of mutually disjoint sets. It then follows from definitions (13), (14) and (15) that if (7), (8) are families of mutually disjoint sets so are $\left\{Y^{k}: 1 \leqq k \leqq n\right\}$ and $\left\{Q^{k}: 1 \leqq k \leqq n\right\}$. Also it follows from the definition of $V^{n}$ that if $\left\{V^{k}: 1 \leqq k<n\right\}$ is a family of mutually disjoint sets, so is $\left\{V^{k}: 1 \leqq k \leqq n\right\}$.

We now show how to define $X^{n+1}, P^{n+1}$, and $U^{n+1}$. Let

$$
\begin{aligned}
& X^{n+1}=f^{-1}\left(\left(Y^{n} \backslash Q^{n}\right) \cup V^{n}\right), \\
& U_{i}^{n+1}=\left(X^{n+1} \cap X_{i}\right) \backslash^{0} X, \\
& U^{n+1}=\bigcup_{i \in I} U_{i}^{n+1} .
\end{aligned}
$$

Since for each $i \in I,\left|X_{i} \backslash^{0} X\right| \leqq a_{i}^{\prime}<\infty, U_{i}^{n+1}$ is a finite set. If for $i \in I$,

$$
a_{i} \leqq\left|X_{i} \backslash\left(\left(X^{0} \backslash \bigcup_{k=1}^{n+1} U^{k}\right) \cup \bigcup_{k=1}^{n} P^{k}\right)\right| \leqq a_{i}^{\prime},
$$

then we define $P_{i}^{n+1}=\varnothing$. Otherwise

$$
\infty>\left|X_{i} \backslash\left(\left(X^{0} \backslash \bigcup_{k=1}^{n+1} U^{k}\right) \cup \bigcup_{k=1}^{n} P^{k}\right)\right|>a_{i}^{\prime} .
$$

But then

$$
\begin{aligned}
\mid\left(\left(X_{i} \backslash X^{0}\right) \backslash \bigcup_{k=1}^{n} P^{k}\right) & \cap{ }^{0} X \mid \\
& \geqq\left|X_{i} \backslash\left(\left(X^{0} \backslash \bigcup_{k=1}^{n+1} U^{k}\right) \cup \bigcup_{k=1}^{n} P^{k}\right)\right|-a_{i}^{\prime},
\end{aligned}
$$

since otherwise

$$
\begin{aligned}
& \left|X_{i} \backslash^{0} X\right| \\
& \quad \geqq\left\{\left|X_{i} \backslash\left(X^{0} \cup^{0} X\right)\right|-\left|\left(\left(X_{i} \backslash X^{0}\right) \backslash \bigcup_{k=1}^{n} P^{k}\right) \cap{ }^{0} X\right|\right\} \\
& \quad+\left\{\left|X_{i} \backslash\left(\left(X^{0} \backslash \bigcup_{k=1}^{n+1} U^{k}\right) \cup \bigcup_{k=1}^{n} P^{k}\right)\right|-\left|X_{i} \backslash^{0} X \cup X^{0}\right|\right\} \\
& >a_{i}^{\prime},
\end{aligned}
$$

which is a contradiction. Hence we can choose $P_{i}^{n+1} \subseteq\left(\left(X_{i} \backslash X^{0}\right) \backslash \bigcup_{k-1}^{n} P^{k}\right)$ $\cap^{0} X$ with 


$$
\left|P_{i}^{n+1}\right|=\left|X_{i}\right\rangle\left(\left(X^{0} \backslash \bigcup_{k=1}^{n+1} U^{k}\right) \cup \bigcup_{k=1}^{n} P^{k}\right) \mid-a_{i}^{\prime} .
$$

Define $P^{n+1}=U_{i \in I} P_{i}^{n+1} \subseteq 0 X \backslash X^{0}$ so that

$$
a_{i} \leqq\left|X_{i} \backslash\left(\left(X^{0} \backslash \bigcup_{k=1}^{n+1} U^{k}\right) \cup \bigcup_{k=1}^{n+1} P^{k}\right)\right| \leqq a_{i}^{\prime} \quad(i \in I) .
$$

It follows from the definitions (16), (17) and (18) that if $\left\{Y^{k}: 1 \leqq k \leqq n\right\}$ and $\left\{Q^{k}: 1 \leqq k \leqq n\right\}$ are families of mutually disjoint sets then since $X^{1} \subseteq^{0} X \backslash X^{0},\left\{X^{k}: 1 \leqq k \leqq n+1\right\}$ is a family of mutually disjoint sets. Also since $U^{1}=\varnothing,\left\{U^{k}: 1 \leqq k \leqq n+1\right\}$ is a family of mutually disjoint sets by (17) and the above. Likewise from the definitions, it follows that $\left\{P^{k}: 1 \leqq k \leqq n+1\right\}$ is a family of mutually disjoint sets. Now define

$$
X^{\prime}=\left(X^{0} \backslash \bigcup_{k=1}^{\infty} U^{k}\right) \cup \bigcup_{k=1}^{\infty} P^{k}
$$

and

$$
Y^{\prime}=\left(Y^{0} \backslash \bigcup_{k=1}^{\infty} V^{k}\right) \cup \bigcup_{k=1}^{\infty} Q^{k}
$$

Since for each $i \in I,\left|X_{i} \backslash\left(X^{0} \cup P^{1}\right)\right|<\infty$ and $P_{i}^{k} \subseteq X_{i} \backslash\left(X^{0} \cup P^{1}\right), k \geqq 2$, all but a finite number of the $P_{i}^{k}$ ( $i$ fixed) are empty. Likewise since $U_{i}^{k} \subseteq X_{i} \backslash^{0} X$ and $\left|X_{i} \backslash^{0} X\right|<\infty$, all but a finite number of the $U_{i}^{k}(i$ fixed) are empty. Hence

$$
a_{i} \leqq\left|X_{i} \backslash X^{\prime}\right| \leqq a_{i}^{\prime} \quad(i \in I) .
$$

In a similar way we derive that

$$
b_{j} \leqq\left|Y_{j} \backslash Y^{\prime}\right| \leqq b_{j}^{\prime} \quad(j \in J) .
$$

Let $x \in X^{\prime}$. If $x \in\left(X^{n} \backslash U^{n}\right) \cup P^{n}$ for some $n \geqq 1$, define $h(x)$ $=g^{-1}(x) \in Y^{n} \subseteq Y^{\prime}$. If $x \notin\left(X^{n} \backslash U^{n}\right) \cup P^{n}$ for any $n \geqq 1$, define $h(x)$ $=f(x) \in Y^{\prime}$. Suppose for $x_{1} \neq x_{2}$ in $X^{\prime}, h\left(x_{1}\right)=h\left(x_{2}\right)$. Since both $f$ and $g$ are injective, we may assume that $x_{1} \in\left(X^{m} \backslash U^{m}\right) \cup P^{m}$ for some $m \geqq 1$ and that $x_{2} \notin\left(X^{n} \backslash U^{n}\right) \cup P^{n}$ for any $n \geqq 1$. Thus $h\left(x_{1}\right)=g^{-1}\left(x_{1}\right)=f\left(x_{2}\right)$ $=h\left(x_{2}\right)$. But then $g^{-1}\left(x_{1}\right) \in Y^{m}$ and $g^{-1}\left(x_{1}\right)=f\left(x_{2}\right) \notin V^{m}$. Hence $x_{2} \in f^{-1}\left(Y^{m} \backslash Q^{m}\right) \subseteq X^{m+1}$. If $x_{2} \oplus^{0} X$, then $x_{2} \in U^{m+1}$ and hence $x_{2} \notin X^{\prime}$, a contradiction. If $x_{2} \in{ }^{0} X$. then $x_{2} \notin U^{m+1}$ and hence $x_{2} \in\left(X^{m+1} \backslash U^{m+1}\right)$ $\cup P^{m+1}$, a contradiction. Thus $h$ is injective.

Suppose $y \in Y^{\prime}$. If $y \in Y^{m}$ for some $m \geqq 1$ then $g(y) \in\left(X^{m} \backslash U^{m}\right)$ $\cup P^{m} \subseteq X^{\prime}$ and $h(g(y))=g^{-1}(g(y))=y$. Otherwise $y \in\left(Y^{0} \backslash \cup_{m=1}^{\infty} Y^{m}\right) \backslash$ $\bigcup_{k-1}^{\infty} \bar{V}_{k}$. Hence $f^{-1}(y) \notin\left(X^{n} \backslash U^{n}\right) \cup P^{n}$ for any $n \geqq 1$ and thus $f^{-1}(y) \in X^{\prime}$ 
with $h\left(f^{-1}(y)\right)=f\left(f^{-1}(y)\right)=y$. Thus $h: X^{\prime} \rightarrow Y^{\prime}$ is a bijection satisfying the conclusion of the theorem.

3. Consequences. The main result of this paper not only contains the original theorem of Banach but also an extension of Banach's theorem given by Knaster and Tarski [4] (cf. [6, pp. 146-147]) and an essentially equivalent theorem of Perfect and Pym [5]. We state it as a corollary, and show how it is a special case.

Corollary 1. Let $X$ and $Y$ be sets. Let $X_{1} \subseteq X$ and $Y_{1} \subseteq Y$ with $f$ : $X_{1} \rightarrow Y$ and $g: Y_{1} \rightarrow X$ injective mappings. Let $\Lambda=\Lambda_{f}-1 \cup \Lambda_{0}$. Then there exist sets $X^{\prime}, Y^{\prime}$ with $X_{1} \subseteq X^{\prime} \subseteq X, Y_{1} \subseteq Y^{\prime} \subseteq Y$ and a bijection $h: Y^{\prime} \rightarrow X^{\prime}$ with graph $\Lambda_{h} \subseteq \Lambda$.

Proof. Let the set $X \backslash X_{1}$ be partitioned into its one element subsets, say $X \backslash X_{1}=\sum_{i \in I} X_{i}$ where $I$ is an index set with $1 \notin I$, so that $X=\sum_{i \in I \cup\{1\}} X_{i}$ is a partition of $X$. Likewise, let the set $Y \backslash Y_{1}$ be partitioned into its one element subsets, say $Y \backslash Y_{1}=\sum_{j \in J} Y_{j}$ where $J$ is an index set with $1 \notin J$, so that $Y=\sum_{j \in J \cup\{1\}} Y_{j}$ is a partition of $Y$. With $i \in I$ associate the integers $b_{i}=0, b_{i}^{\prime}=1$, and with 1 associate the integers $b_{1}=0, b_{1}^{\prime}=0$. With $j \in J$ associate the integers $a_{j}=0$, $a_{j}^{\prime}=1$, and with 1 associate the integers $a_{1}=0, a_{1}^{\prime}=0$. Then $f^{-1}: f\left(X_{1}\right)$ $\rightarrow X_{1}$ is a bijection with

$$
\begin{aligned}
& \left|X_{1} \backslash X_{1}\right| \leqq b_{1}^{\prime}=0, \quad\left|X_{i} \backslash X_{1}\right| \leqq b_{i}^{\prime}=1 \quad(i \in I), \\
& 0=a_{1} \leqq\left|Y_{1} \backslash f\left(X_{1}\right)\right|, \quad 0=a_{j} \leqq\left|Y_{j} \backslash f\left(X_{1}\right)\right| \quad(j \in J) .
\end{aligned}
$$

Likewise $g^{-1}: g\left(Y_{1}\right) \rightarrow Y_{1}$ is a bijection with

$$
\begin{gathered}
0=b_{1} \leqq\left|X_{1} \backslash g\left(Y_{1}\right)\right|, \quad 0=b_{i} \leqq\left|X_{i} \backslash g\left(Y_{1}\right)\right| \quad(i \in I), \\
\left|Y_{1} \backslash Y_{1}\right| \leqq a_{1}^{\prime}=0, \quad\left|Y_{j} \backslash Y_{1}\right| \leqq a_{j}^{\prime}=1 \quad(j \in J) .
\end{gathered}
$$

Hence by the theorem there exists $X^{\prime} \subseteq X, Y^{\prime} \subseteq Y$ and a bijection $h: Y^{\prime} \rightarrow X^{\prime}$ with $\Lambda_{h} \subseteq \Lambda_{f}^{-1} \cup \Lambda_{o}$ with, in particular,

$$
0=b_{1} \leqq\left|X_{1} \backslash X^{\prime}\right| \leqq b_{1}^{\prime}=0, \quad 0=a_{1} \leqq\left|Y_{1} \backslash Y^{\prime}\right| \leqq a_{1}^{\prime}=0 .
$$

Hence $X_{1} \subseteq X^{\prime}$ and $Y_{1} \subseteq Y^{\prime}$. Thus the corollary is a special case of the theorem.

We now give an application of the main result to transversal theory. Let $\mathfrak{A}(I)=\left(A_{i}: i \in I\right)$ be a family of subsets of a set $E$. Here $I$ is an index set, and it is possible that $A_{i}=A_{i}{ }^{\prime}$ for $i \neq i^{\prime}$ in $I$. A family $\left(e_{i}: i \in I\right)$ is a system of distinct representatives of the given family $\mathfrak{A}(I)$ provided $e_{i} \in A_{i}(i \in I)$ and the elements $e_{i}(i \in I)$ are distinct. The set $\left\{e_{i}: i \in I\right\}$ is a transversal of $\mathfrak{A}(I)$. If $|E|<\infty$ and $|I|<\infty$ and $E=\sum_{j=1}^{p} E_{j}$ is a partition of $E$ with associated integers $0 \leqq b_{j} \leqq b_{j}^{\prime}$, then A. J. Hoffman and H. W. Kuhn [3] gave necessary and suffi- 
cient conditions that the family $\mathfrak{A}(I)$ have a transversal $\left\{e_{i}: i \in I\right\}$ with $b_{j} \leqq\left|E_{j} \cap\left\{e_{i}: i \in I\right\}\right| \leqq b_{j}^{\prime}(1 \leqq j \leqq p)$.

A consequence of their conditions, as was noted in [2], is that if there is a transversal $\left\{e_{i}^{\prime}: i \in I\right\}$ with $b_{j} \leqq\left|E_{j} \cap\left\{e_{i}^{\prime}: i \in I\right\}\right|, 1 \leqq j \leqq p$, and a transversal $\left\{e_{i}^{\prime \prime}: i \in I\right\}$ with $\left|E_{j} \cap\left\{e_{i}^{\prime \prime}: i \in I\right\}\right| \leqq b_{j}^{\prime}, 1 \leqq j \leqq p$, then there is a transversal with the above properties. In fact the Hoffman-Kuhn theorem is a special case of the so-called symmetric supply-demand theorem [2], which can indeed be used to derive our main result in case the sets $X$ and $Y$ are finite. It is in fact the symmetric supply-demand theorem which led the author to the main result of this paper. The following corollary extends the aspect of the Hoffman-Kuhn theorem mentioned above. It is an immediate consequence of the main result.

Corollary 2. Let $\mathfrak{A}(I)=\left(A_{i}: i \in I\right)$ be a family of subsets of a set $E$ and let $E=\sum_{j \in J} E_{j}$ be a partition of $E$. Let integers $0 \leqq b_{j} \leqq b_{j}^{\prime}$ be given for each $j \in J$. Suppose there is a subfamily $\left(A_{i}: i \in I_{0}\right)$ of $\mathfrak{A}(I)$ which has a transversal $\left\{e_{i}^{\prime}: i \in I_{0}\right\}$ with

$$
\left|E_{j} \backslash\left\{e_{i}^{\prime}: i \in I_{0}\right\}\right| \leqq b_{j}^{\prime} \quad(j \in J),
$$

and suppose $\mathfrak{A}$ has a transversal $\left\{e_{i}^{\prime \prime}: i \in I\right\}$ with

$$
b_{j} \leqq\left|E_{j} \backslash\left\{e_{i}^{\prime \prime}: i \in I\right\}\right| \quad(j \in J),
$$

then $\mathfrak{A}$ has a transversal $\left\{e_{i}: i \in I\right\}$ with

$$
b_{j} \leqq\left|E_{j} \backslash\left\{e_{i}: i \in I\right\}\right| \leqq b_{j}^{\prime} \quad(j \in J) .
$$

Of course, the complete main result may be translated into the language of transversal theory.

\section{REFERENCES}

1. S. Banach, Un théorème sur les transformations biunivoques, Fund. Math. 6 (1924), 236-239.

2. L. R. Ford, Jr. and D. R. Fulkerson, Flows in networks, Van Nostrand, Princeton, N. J., 1962.

3. A. J. Hoffman and H. W. Kuhn, On systems of distinct represenatives, Ann. of Math. Studies, No. 38, Princeton Univ. Press, Princeton, N. J., 1956, pp. 199-206.

4. B. Knaster, Un theoreme sur les fonctions d'ensembles, Ann. Polon. Math. 6 (1927), 133

5. Hazel Perfect and J. S. Pym, An extension of Banach's mapping theorem, with applications to problems concerning common representatives, Proc. Cambridge Philos. Soc. 62 (1966), 187-192.

6. W. Sierpinski, Algèbra des ensembles, Monografie Mat. No. 23, PWN, Warsaw, 1951.

UNIVERSITY OF WISCONSIN 